5 Anonymous. Hypertension in the elderly [Editorial]. Lancet 1977;i:684-5.

6 Stewart IMcDG. Relation of reduction in pressure to first myocardial infarction in patient treatment for severe hypertension. Lancet 1979; i:861-5.

7 Cruickshank JM, Thorp JM, Zacharias FJ. Benefits and potential harm of lowering high blood pressure. Lancet 1987; ii:581-4.

8 Samuelson $\mathrm{O}$, Wilhelmson L, Anderson OK, Pennert K, Berglund G. Cardiovascular mortality in blood pressure and serum cholesterol levels in treated hypertension. Results from the Primary Prevention Trial in Göteborg. YAMA 1987;258:1768-76.

9 Waller PC, Isles CG, Lever AF, Murray GD, McInnes GT. Does therapeutic reduction in diastolic blood pressure cause death from coronary heart disease? Joumal of Human Hypertension 1988;2:7-10.

10 Fletcher AE, Beevers DG, Bulpitt CJ, et al. The relationship between a low treated blood pressure and IHD mortality: a report from the DHSS Hypertension Care Computing Group (DHCCP). fournal of Human Hypertension 1988;2:11-5.

11 Management Committee. Report. The Australian therapeutic trial in mild hypertension. Lancet $1980 ; \mathrm{i}: 1261-7$.
12 Hypertension Detection and Follow-up Program Collaborative Group. Hypertension Detection and Follow-up Program. I. Reduction in mortality of persons with high blood pressure including and Follow-up Program. 1. Reduction in mort

13 Medical Research Council Working Party. MRC trial of treatment of mild hypertension: principal results. Br Med f 1985;291:97-104.

14 IPPPSH Collaborative Group. Cardiovascular risk and risk factors in a randomised trial of treatment based on the beta blocker oxprenolol. $f$ Hypertens 1985;3:379-92.

15 Amery A, Birkenhäger W, Brixko P, et al. Mortality and morbidity results from the European working party on high blood pressure in the elderly trial. Lancet 1985; i: 1349-59.

16 Coope J, Warrender TS. Randomised trial of treatment of hypertension in elderly patients in primary care. Br Med f 1986;293:1145-51.

7 Coope J, Warrender TS. Lowering blood pressure. Lancet 1987;ii:518.

8 Hundson MF. How often can antihypertensive treatment be discontinued? fournal of Human Hypertension 1988;2:65-9.

19 Fletcher AE, Franks PJ, Bulpitt CJ. The effect of withdrawing antihypertensive therapy: a review. f Hypertens 1988;6:431-6.

\title{
Controlling the carcinoid syndrome
}

\author{
Simple blocking drugs, somatostatin, and then perhaps embolisation
}

Patients with the carcinoid syndrome experience flushing and diarrhoea and sometimes wheezing and progressive right heart failure. The symptoms are caused by the products of carcinoid tumours derived from the foregut or midgut reaching the general circulation. Rarely the syndrome occurs without secondary spread of the tumour (when the venous drainage from a primary carcinoid tumour directly enters the systemic circulation), but most patients have hepatic metastases. Patients with secondary carcinoid deposits survive, however, much longer than patients with secondary adenocarcinoma, and treating the distressing symptoms produced by circulating products from tumours is therefore well worth while. Survival for 15 to 20 years is well recognised, and in some series the mean survival has been as long as eight years from presentation, though three to five years is more usual. ${ }^{1}$ Various approaches to palliating the carcinoid syndrome have been advocated, but there is little agreement on their comparative value.

Conventional radiotherapy to reduce the mass of hepatic tumours is generally agreed to be ineffective at tolerable doses, ${ }^{2}$ though targeting radioactive isotopes with labelled precursors of tumour products is being explored. ${ }^{3}$ Surgical resection is rarely possible as deposits of tumours are generally multiple and in both hepatic lobes. Partial hepatectomy may be considered in roughly one in 10 patients who have the disease predominantly in one lobe. ${ }^{4}$ Alternatively, successful debulking may be achieved by "shelling out" a few large secondaries. ${ }^{5}$ Two problems are that the patients most capable of withstanding a major operation are likely to have a better prognosis than the average and that the release of tumour products during the operation makes it hazardous.

The best results of conventional cytotoxic chemotherapy are currently achieved with combinations of agents, usually including streptozocin. Shrinkage of the tumour or a reduction in circulating tumour products occurs in about a quarter to two fifths of patients, but the price in toxicity deters even enthusiasts. ${ }^{6}$ Human leucocyte interferon given thrice weekly is reported to induce objective responses in about half of the patients ${ }^{7}$ : the disease stabilised or partially remitted for two to three years in the patients who responded. The side effects-predominantly malaise and mild pancytopenia after an initial syndrome like flu had resolved-may be more acceptable than those of conventional chemotherapy.

The dependence of deposits of hepatic tumour on arterial blood flow has initiated three other approaches to debulking tumours. Ligating the hepatic artery at laparotomy tends to be ineffective as the many arterial collaterals rapidly replace the flow from the hepatic artery. Ligating the collaterals as well is a formidable but feasible procedure. ${ }^{8}$ An interventional radiological technique (using multiple emboli through the hepatic artery to obliterate the intrahepatic arterial tree) is a less hazardous option. Many centres have used this procedure since it was first reported in $1977 . .^{\circ}$ Sustained relief of symptoms may be expected for two to 18 months after embolisation, and the procedure may be repeated. ${ }^{10}$ Local symptoms from painful metastases may be relieved. Scrupulous medical care is required before and during the procedure to prevent dangerous circulatory changes after necrosis of the tumour. Embolisation, however, has a mortality of about 3\% and has not been shown to prolong survival. ${ }^{11}$

Rather than reducing the mass of the tumour, the alternative approach is to use drugs to block the synthesis, release, or peripheral actions of the circulating tumour products. Serotonin (5-hydroxytryptamine), the classic mediator, now merely heads a list of potentially active substances that are synthesised and released from carcinoid tumours. The list includes tumour kallikrein, tachykinins, substance $\mathbf{P}$ and other neuropeptides, prostaglandins, and catecholamines. ${ }^{12}$ The varying symptoms of different patients is probably explained by them having differing profiles of active substances, but the relative contribution of these substances to each symptom remains contentious. Treatment with drugs is thus largely empirical.

Recent advances may allow treatment to become less empirical-for example, different classes of serotonin receptor have now been delineated.$^{13}$ Of the drugs that block the 5-hydroxytryptamine type 2 receptor, cyproheptadine often helps the diarrhoea ${ }^{14}$ and ketanserin sometimes but not always helps the flushing. ${ }^{15}$ An antagonist of the 5-hydroxytryptamine type 3 receptor also reduces diarrhoea. ${ }^{16}$ These drugs are generally better tolerated than $p$-chlorphenylalanine, which inhibits synthesis of serotonin, and they may be used with other agents such as antihistamines and non-specific antidiarrhoeal drugs.

A long acting analogue of somatostatin has now emerged as a powerful treatment for the syndrome but is not yet generally available in Britain. Giving the drug thrice daily by subcutaneous injection relieves flushing, diarrhoea, and wheezing in up to four fifths of patients. ${ }^{17}$ The broad effectiveness of somatostatin reflects its multiple actions: it reduces the release of active substances and blocks their peripheral action. Shrinkage of the tumour has even been reported in a few patients. The disadvantages of somatostatin are that progressively larger doses are needed to control symptoms and eventually side effects such as diarrhoea may limit its use. 
Clinical trials are particularly taxing in patients with the carcinoid syndrome. Studies of the impact of treatment on mortality are difficult because survival may be prolonged and the range is wide. The rarity of the disease also means that such studies cannot be done in a single centre. Comparative studies that measure the quality of life are also difficult because patients vary so much in both the severity and their tolerance of symptoms. Studies at different times in the same patient may, however, be valuable.

The best policy at the moment seems to be to control mild symptoms if necessary with simple blocking drugs and then to resort to somatostatin when these are no longer enough. Embolisation of the hepatic artery or chemotherapy should be considered when somatostatin is no longer effective.

H J F HODGSON

Reader in Gastroenterology,

Royai Postgraduate Medical School,

London W12 0HS
2 Keane TS, Rider WS, Harwood HR. Whole abdominal irradiation in the management of metastatic gastrointestinal carcinoid tumour. Int f Radiat Oncol Biol Phys 1981;7:1519-21.

Kimming BN, Georgi P, Adolph JMG, Zum Winkel K. Carcinoid tumours, CT and 131 I-me

Galland RB, Blumgart LH. Surgical management of carcinoid syndrome. Br 7 Hosp Med 1986;35: 166-70.

5 Stephen JL, Graeme-Smith DG. Treatment of the carcinoid syndrome by local removal of hepatic metastases. Proceedings of the Royal Society of Medicine 1972;65:444-5.

6 Kvols LK. Metastatic carcinoid tumours and the carcinoid syndrome. Am $\mathcal{G}$ Med 1986;81:49-55.

Oberg K, Norheim I, Lind E, et al. Treatment of malignant carcinoid tumours with human leucocyte interferon. Long-term results. Cancer Treat Rep 1986;70:1297-304.

8 Bengmark S, Fredlund $P$, Hafström L, Vang J. Present experiences with hepatic dearterialization in liver neoplasm. Progress in Surgery 1974;13:141.

9 Allison DJ, Modlin IM, Jenkins WJ. Treatment of carcinoid liver metastases by hepatic artery embolization. Lancet 1977; ii:1323-5.

10 Maton PN, Camilleri M, Griffin G, Allison DJ, Hodgson HJF, Chadwick VS. Role of hepatic artery embolisation in the carcinoid syndrome. Br Med $\mathcal{F} 1983 ; 287: 932-5$.

11 Coupe M, Hemmingway A, Hodgson HJF, Allison DJ. Effect of hepatic artery embolisation on survival in carcinoid syndrome. Gut 1987;28:A1329.

12 Hodgson HJF, Maton PN. Carcinoid and neuroendocrine tumours. Baillieres Clin Gastroenterol 1987;1:35-61.

13 Bradley PB, Engel G, Feniuk W, et al. Proposals for the classification and nomenclature of functional receptors for 5-hydroxytryptamines. Neuropharmacology 1986;25:563-76.

14 Vroom FQ, Brown RE, Dempsey H, Hill SR. Studies on several possible antiserotonin agents in a patient with the functioning carcinoid syndrome. Ann Intem Med 1962;65:941-5.

15 Gustafsen J, Lendorf A, Raskov H, Boesby S. Ketanserin versus placebo in carcinoid syndrome. Scand f Gastroenterol 1986;21:816-8.

16 Coupe MO, Anderson JV, Morris JA, Alstead EM, Bloom SR, Hodgson HJF. The effects of the 5-hydroxytryptamine $\left(\mathrm{SHT}_{3}\right)$ receptor antagonist ICS $205-930$ in the carcinoid syndrome. Alimentary Pharmacology and Therapeutics 1988;2:167-72.

17 Kvols LK, Moertel CG, O'Connell MJ, Schute AJ, Rudin J, Hahn RG. Treatment of the malignan carcinoid syndrome: evaluation of a long-acting somatostatin analogue. $N$ Engl f Med 1986;315:633-6.

\section{New Zealand proposals to unshackle hospitals}

\section{Suggestions to make regional health authorities purchasers of services}

In New Zealand a taskforce comprising Mr Alan Gibbs, Dame Dorothy Fraser, and Sir John Scott has taken a hard look at the organisation of the hospital services. The resulting report is hard hitting and radical. ' It carries some echoes of the Griffiths report, ${ }^{2}$ which it quotes approvingly, but takes a further step that is relevant to the current health services review in Britain.

From the mid-1950s to the 1960s New Zealand had an outstanding health service by world standards. In the 1970s the service deteriorated as New Zealand's economic position declined. Like the British National Health Service, New Zealand's hospital system is essentially publicly owned, administered, and financed. Successive governments held expenditure down, while the calls on the hospitals increased.

The deterioration seems to have been even sharper in New Zealand than in Britain. For example, waiting times increased substantially between December 1978 and December 1987. Not only did the number of people waiting rise by a quarter but also they had on average to wait much longer. The taskforce cites individual examples of over two and a half years for a hip replacement, two years for a cataract operation, two years for a knee replacement, and 18 months for a hernia repair.

The Gibbs taskforce is highly critical of the current performance of New Zealand's hospital system because it does not offer equal access; makes some people wait much too long for treatment; is not sufficiently responsive to changes in public preferences; provides inadequate support to elderly people and others to keep them out of hospital; and is poorly integrated with primary health care. These criticisms are similar to those levelled against the British hospital service.

Arthur Andersen and Company was commissioned to produce a supplementary report on the efficiency of the hospital system. ${ }^{3}$ Using conventional performance measures, the company suggested that large savings could be madebetween $24 \%$ and $32 \%$ of current operating expenses. The methods are open to many criticisms, and the potential savings are certainly exaggerated. Nevertheless, you cannot quarrel with the taskforce's comment that: "There was an appalling absence [in the hospital system] of the kind of data needed to enable the sector to be managed. There was, in fact, little consideration given to the issue of management at all by the health service as a whole."

The resemblance to the Griffiths report is not merely in the bluntness of the language. The taskforce recommends general management in place of the triumvirate-a doctor, a nurse, and an administrator - who currently comprise each hospital's chief executive and operate by consensus. The taskforce remarks: "The troika concept was imported originally from the United Kingdom, where, sensibly, they have now abandoned it." Several other recommendations (such as a rapid improvement in management information) also sound familiar.

What is new, however, and relevant to the British health service review is a proposal to separate financing and provision. "The Ministry of Health would deal solely with policy advice to the minister. The rest of the system would be funded from central government through a newly established National Health Commission to six regional health authorities on a population basis. The six regional health authorities would purchase publicly funded health services from hospitals and other health providers on behalf of the people in their regions. They would not manage or own any services but would contract with public, private and voluntary providers on a competitively neutral basis."

To put the area health boards on an equal starting base (with each other and with private companies) their assets would be valued, target rates of financial return would be prescribed, and financial reporting requirements would be laid down. They would also have freedom to raise loans but without government guarantee. In due course some form of independent ownership for them would be worked out.

The National Health Commission will set up one or more independent professional review organisations to monitor and 